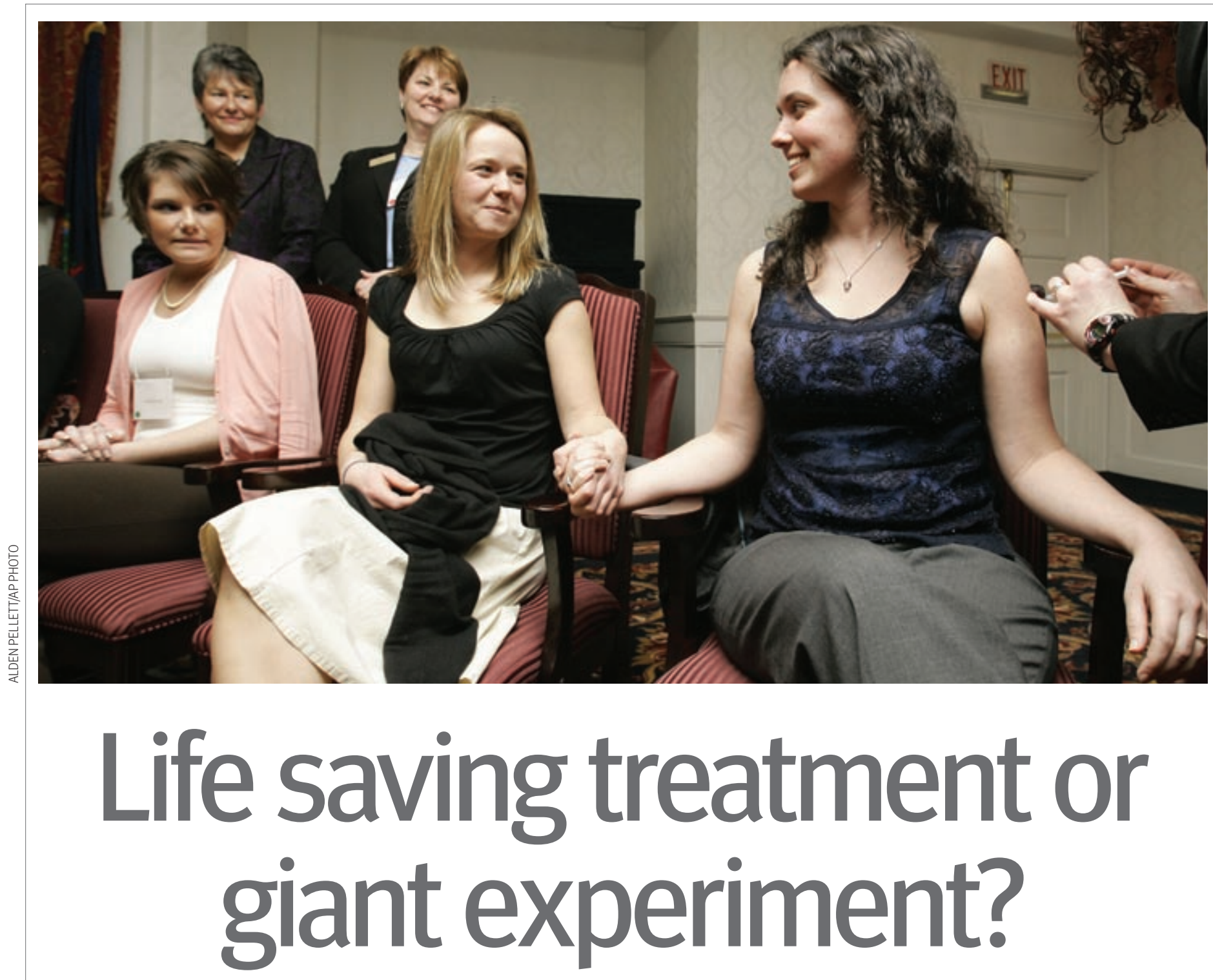

Many countries are considering mass vaccination of young girls, but Rebecca Coombes reports that proposals for mandatory immunisation in the US have raised concerns, and not just among religious conservatives

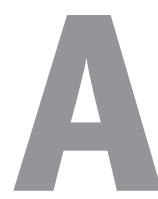

vaccine that promises protection against a common female cancer-what could possibly be controversial about that? Plenty, if the vaccine in question targets a sexually transmitted infection that causes 70\% of cervical cancers and, to be most effective, should be given to girls as young as 10 before they become sexually active. ${ }^{1}$

The vaccine is Merck's Gardasil, which protects against four strains of human papillomavirus: types 16 and 18 , responsible for $70 \%$ of all cervical cancers, and types 6 and 11 , which cause $90 \%$ of cases of genital warts. ${ }^{1}$ Three injections provide protection for at least five years, but the vaccine is expensive at about $\$ 360$ (£185; €280) a shot.

The vaccine is undoubtedly set to be a blockbuster product for Merck. Twenty

US states are considering bills that would make the immunisation a requirement for school attendance, which could net Merck billions of dollars. ${ }^{2}$ With a rival vaccine (Cervarix) from GlaxoSmithKline due to be approved in the next year, Merck has been engaged in some heavy lobbying of its product www.gardasil.com. Health freedom organisations, among other critics, have condemned Merck's "strong arm" marketing methods, claiming the company hopes to use profits from Gardasil to fund the huge litigation costs it has had to pay over rofecoxib (Vioxx). ${ }^{3}$ And last week the vaccine made front page news in the United Kingdom with a Guardian story questioning Merck's motives in funding a summit on cervical cancer in Paris for doctors and patient organisations. ${ }^{4}$

Plans for mass vaccination with Gardasil are already well advanced around the world. Approved by the Food and 
Drug Administration in June 2006, the vaccination has the green light in Australia, New Zealand, Canada, Mexico, and EU countries.

But in the United States the vaccine has come up against strong opposition. The furore has centred on plans to make the vaccination a mandatory requirement for preteen girls-a move that critics say ignores parental choice, could promote underage sex, and runs counter to policies in some states that encourage young people to abstain from sex until marriage. The row first ignited in Texas, where a surprise edict to make vaccination compulsory for schoolgirls by Texas governor Rick Perry was overturned by the state House of Representatives. ${ }^{5}$ It propelled Gardasil on to the front pages and led to editorials in the New York Times and the Washington Post.

Mr Perry insisted that his plan was no different from vaccinating children against polio. "The HPV vaccine provides us with an incredible opportunity to effectively target and prevent cervical cancer," he said. The governor's spokeswoman Krista Moody told the New York Times: "The governor believes we should protect as many young women as possible-rich and poor, insured and uninsured-while maintaining parents' right to opt their daughter out of receiving the vaccine."

But opponents said that Mr Perry's order intruded into family life. "Let's continue to allow only parents and children and doctors to decide if this is right for you," conservative republican Dennis Bonnen told the Houston Chronicle.

But this wasn't quite the bruising showdown with America's religious right wing that some newspapers have billed. Although the conservatives did have concerns, what really inflamed critics was Mr Perry's links with Merck. Mr Perry, it emerged, had received campaign money from Merck, and his former chief of staff had become a Merck lobbyist. ${ }^{6}$

As a result of the Texan revolt, Merck has backed off pushing for mandatory vaccination, saying it would instead provide vaccine information only if requested by government officials.

In Illinois, a similar bill sponsored by the senate's majority leader, Debbie Halvorson, also drew flak. An editorial in the Illinois

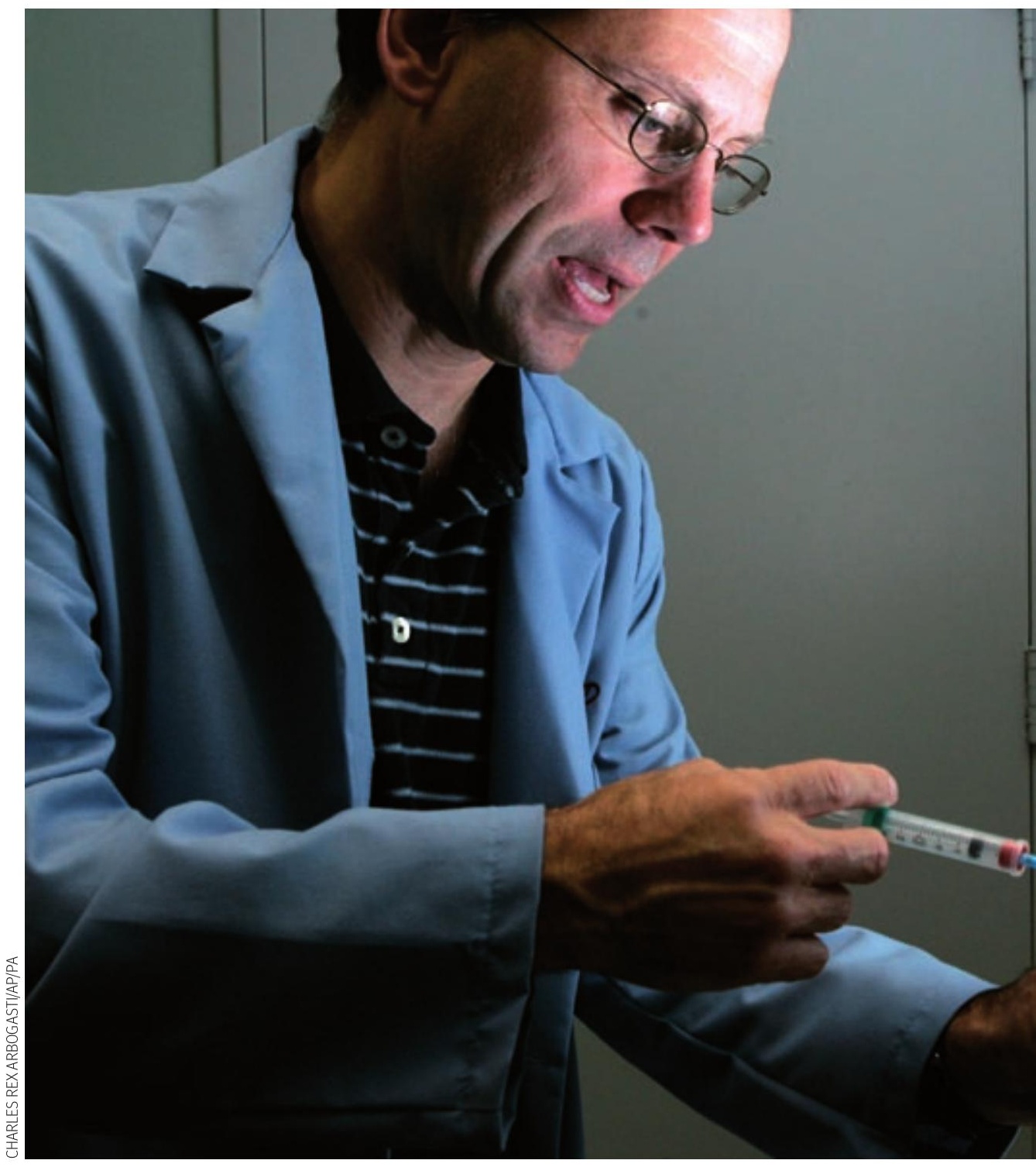

newpaper Register-News pointed out: "Halvorson is also the director of Women in Government, a national cancer-fighting group which has received funding from Merck." In California, politicians pulled a bill for revision over concerns about parental rights and the lack of a long safety record for the new vaccine.

Some may wonder what all the fuss is about. None of the bills under debate in the US would actually lead to forced vaccination-all include an opt-out clause for concerned parents. Even two of the largest conservative family groups-Focus on the Family and the Family Research Council-say they have no problem with the vaccine, only if there is no parental opt out. No surprise then that a New Mexico bill that will usher in mandatory immunisation is on the verge of being signed by the governor. The Virginia governor has said he would sign a similar bill. Very sensible, said the Washington Post. "Parents will have the final say. They won't have to cite any reason and no student will be kept out of school because her parents decided against shots. For a virus so widespread and potentially harmful, an opt-out regime, which will lead to higher rates of immunization than one asking parents to opt-in, makes sense."

Sarah Brown, director of the National Campaign to Prevent Teen Pregnancy, told the Baltimore Sun: "How do we feel about our children being required to receive a vaccine without a lot of long term data on its effects? I understand that . . . But the idea that a vaccine is going to change a woman's calculus about whether to have sex or not strikes me as intensely unreasonable."

In a nifty bit of timing, a new study by the Centers for Disease Control and Prevention shows that at least 25 million girls and 


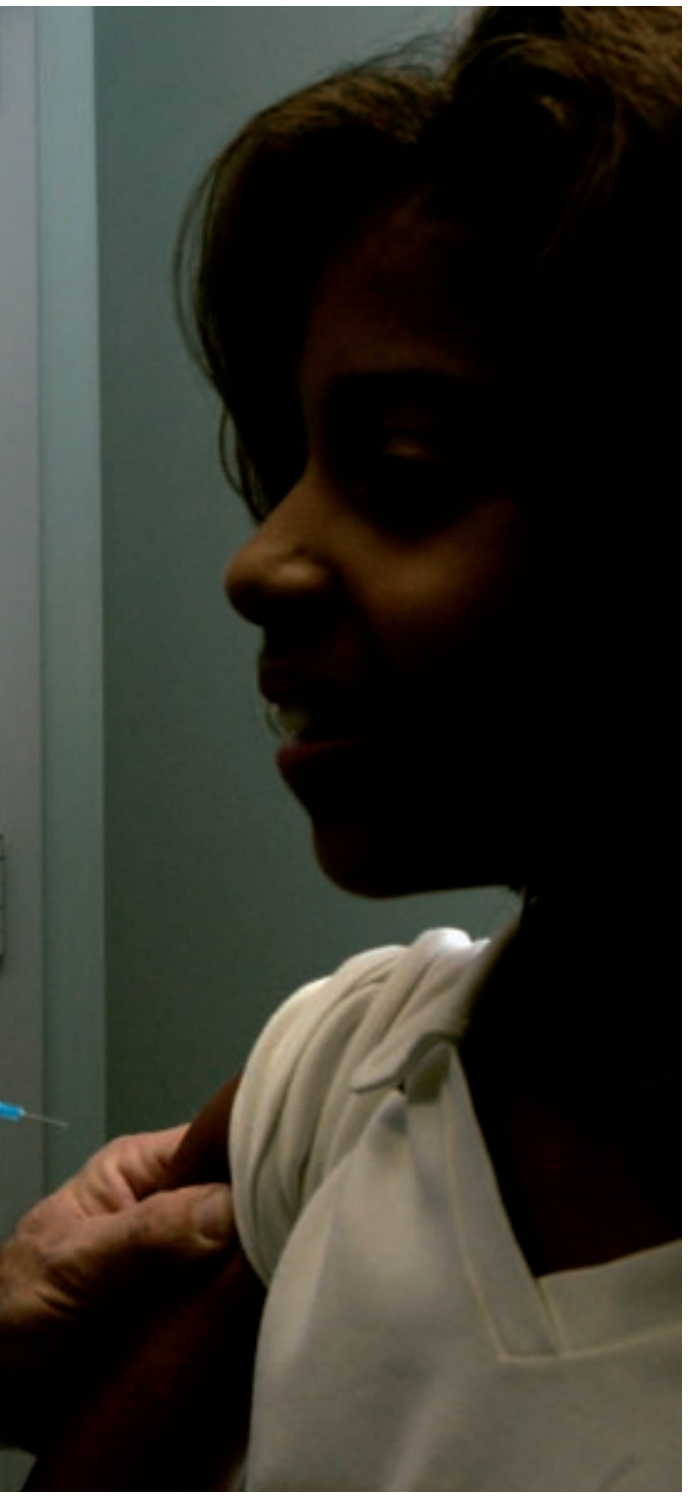

women-or about one in four from age 14 to 59-are infected with at least one type of human papillomavirus. ${ }^{7}$

\section{Global reach}

In Australia, the vaccine has had an easier ride. The first government funded vaccination campaign started there this year, targeting all 12-13 year old girls. For the first two years there is also a free "catch up" programme for women up to 26.

Ian Frazer, the immunologist who created Gardasil and director of the department of medicine at Princess Alexandra Hospital, Brisbane, told the $B M J$ that objection had been "minimal."

"Senator Barnaby Joyce implied that the vaccine should not be given to under 18 year olds because it encouraged promiscuity. However, he rapidly changed his mind in the face of public opinion," he said.

\section{"We should protect as many young women as possible -rich and poor, insured and uninsured"}

Elsewhere, Canada's latest federal budget includes \$C300m (£130m; €190m; \$260m) for the vaccine. In the UK, Gardasil is licensed for use in girls as young as 9 and can be bought from private clinics. The NHS has yet to provide the vaccination for free-leading to claims that the government is dragging its feet. Minutes of the Joint Committee on Vaccination and Immunisation show that it is in favour of "vaccination of girls at the age of 11 or 12 years with HPV vaccine." ${ }^{\circ}$ The minutes also reveal that cost implications are stalling a final decision.

In the developing world-which has much of the burden of cervical cancer disease and practically no screening programmes-there are hopeful signs that the vaccine will be widely introduced. Professor Frazer said: "The offer of vaccine at cost from the two major manufacturers and support from the Bill and Melinda Gates Foundation, together with imminent endorsement by UICC [International Union against Cancer] and WHO for global immunisation should help." He is involved in plans to introduce the vaccine on the south Pacific island of Vanuatu, to test the feasibility of immunising pre-teens in the developing world.

But there is concern for less poor countries that don't qualify for funding from the GAVI Alliance, which supports childhood vaccination programmes. Eduardo Franco, director of the division of cancer epidemiology at McGill

University, Montreal, told the BMJ: "HPV vaccines will not be subsidised in the 'middle resource' countries, such as Brazil, Mexico, Argentina, and India. They do have the required training and screening infrastructures in place. Yet these countries continue to experience high morbidity and mortality because one or more items in the chain of resources needed for effective screening have failed."

Professor Franco said that the "cruel logic" was that the women who stood to benefit from the vaccine-and pass the message on to their daughters-were those who can afford high quality private health care and already get regular smear tests. "But those women who cannot afford private health care and thus have to depend on the public system (which has low quality, spotty, or non-existent screening) are not being screened adequately or at all. They do not know about HPV vaccines; nor will their daughters be offered vaccination. These are women who, today, develop invasive cervical cancer in these countries."

\section{Safety concerns}

Despite the enthusiasm, there have been inevitable questions over the vaccine's safety. One Merck funded researcher, Diane Harper, has received publicity for saying that giving the vaccine to 11 year old girls is "a great big public health experiment." Although praising the vaccine, Dr Harper feared that young women would develop a false sense of security and stop having smear tests.

But Professor Frazer said the vaccine's safety record was sound, although he acknowledged that ongoing monitoring is required: "The safety record over five years and 250000 women in controlled trials is pretty impressive, and while the CDC [Centers for Disease Control] report of adverse events possibly vaccine associated had a little press, it was mostly balanced, with commentary that it amounted mostly to fainting and the three cases of Guillain Barré among two million doses over six months was no higher than would be expected by chance in a similar cohort of young women.

"I've provided vaccine for my children and don't see it as an experiment but rather a prudent exercise in risk management." Rebecca Coombes is a freelance journalist, London rcoombes@bmigroup.com

\section{Competing interests: None declared.}

1 Lowy D, Schiller J. Prophylactic human papillomavirus vaccines. J Clin Invest 2006;116:1167-73.

2 Carreyrou J. Moves to vaccinate girls for cervical cancer draw fire. Wall Street Journal 2007 Feb 7.

3 Alliance for Human Research Protection: Facts behind Merck's mandatory vaccine campaign to help pay for Vioxx. http://ahrp.blogspot.com/2007/02/factsbehind-mercks-mandatory-vaccine.htm

4 Boseley S. Vaccination campaign funded by drug firm. Guardian 2007 Mar 26.

5 Hopkins Tanne J. Texas governor is criticised for decision to vaccinate all girls against HPV. BMJ 2007;334:332-3.

6 Frosch D. Texas house rejects order by governor on vaccines. New York Times 2007 Mar 14

7 Dunne E, Unger E, Sternberg M, McQuillan G, Swan D, Patel S, et al. Prevalence of HPV infection among females in the United States. JAMA 2007;297:813-9.

8 Joint Committee on Vaccination and Immunisation. Minutes of the HPV sub group meeting, 22 September 2006. www.advisorybodies.doh.gov.uk/jcvi/mins hpv-220906.htm. 